\title{
PERIPHERAL VASOMOTOR FUNCTION IN CRETINISM
}

\author{
BY \\ B. D. BOWER \\ From the Department of Paediatrics and Child Health, University of Birmingham, and the Children's Hospital, \\ Birmingham
}

(RECEIVED FOR PUBLICATION FEBRUARY 11, 1957)

\begin{abstract}
'Diminution or stasis of the peripheral circulation are usually manifested by striking changes in the appearance of the skin and mucous membranes. The skin is pale and cool and often has a grayish mottled appearance. ... A warm, moist skin and a high, ruddy colour are strong evidences against thyroid deficiency.'
\end{abstract}

These features of poor peripheral circulation which Lawson Wilkins (1950) emphasizes in his description of hypothyroidism in childhood are well-known physical signs and, as he says, are often of diagnostic value. They are usually included in a description of the bradycardia, hypotension and other signs of a slowly functioning cardiovascular system in textbook descriptions of the disease, and it is thereby implied that the skin is cold and cyanosed because of poor cardiac output. Yet another explanation is possible. They might be due to absence or inadequacy of the vasodilatation reflex, so that warm stimuli on any part of the body surface, which would normally initiate general vasodilatation in the skin, fail to do so. Indeed, a depression of vasomotor reflexes might be expected in a disease where all functions, in particular other reflexes and evidences of nervous activity, are depressed. However, no experimental study of vasomotor reflexes in hypothyroidism has been found in the literature. Talbot (1931) studied the resting skin temperatures of 10 untreated cases, 22 treated cases and 27 normals, and confirmed the lower skin temperature in the cretins. The difference was particularly marked at the extremities. $\mathrm{He}$ then exposed them nude to room temperature and found that the average fall at the extremities was less than occurred in normals. There are several possible explanations for this result, but at least it can be concluded that there was no evidence of an exaggerated vasoconstrictor response to cold, which would be one possible explanation of poor peripheral circulation.

The present investigation was undertaken to find out whether reflex vasodilatation is impaired in cretinism. Five cases of previously untreated cretinism and one case of treated cretinism were investigated before and at intervals during treatment.

\section{Method of Investigation}

A modification of the limb-immersion method of Gibbon and Landis (1932) was used for those infants and young children unable to cooperate. Details of technique will be found elsewhere (Bower, 1954, 1956). Briefly the method is as follows:

The infant is undressed and secured on a canvas sheet on his right side, his arm passing through a hole in the canvas into a heat-lagged can containing water at 42 to $44^{\circ} \mathrm{C}$. Thermocouples measure the temperature of the feet and unimmersed hand at intervals before and during arm immersion, which is continued until either the temperature of the unimmersed extremities has reached a maximum or it is clear that the response is absent or grossly delayed. Hand temperature is taken from the skin on the dorsum of the hand just proximal to the metacarpophalangeal joints between the second and third metacarpals, and foot temperature from a corresponding point on the foot between the first and second metatarsals. Thermocouples are also used throughout the experiment to measure the temperature of the air above the cot and the water in the can and the temperature of the latter is maintained at 42 to $44^{\circ} \mathrm{C}$. by frequent partial replacement of the cooling water with hot water.

Those children old enough to cooperate sit on a chair with the right arm in a basin of water at 42 to $44^{\circ} \mathrm{C}$. Temperatures are recorded in the same way as in the infants.

Three values are then obtained from the timetemperature graph of each limb (Fig. 1):

$T_{R}=$ the time interval between arm immersion and the start of reflex temperature rise (minutes)

$\mathrm{T}_{\max }=$ the time interval between arm immersion and the attainment of a maximum temperature (minutes)

m.t. $=$ the maximum temperature attained $\left({ }^{\circ} \mathrm{C}\right.$. $)$

It is theoretically desirable to perform each experiment at the same environmental temperature and to start heating the limb only when the skin temperatures of the unimmersed extremities are at standard levels. However, in practice it has been found that under the condi- 
tions of these experiments room temperature and initial limb temperatures are unimportant factors in determining the nature of the response by comparison with the heating stimulus applied to the immersed limb.

\section{The Normal Response in Infancy and Childhood}

Reflex vasodilatation occurs as rapidly and completely in the normal child and in the normal infant over approximately 3 months of age as in the adult (Bower, 1954, 1956). With the method of investigation described, this adult type of response fulfils the following criteria: $T_{R}($ feet) is less than 15 minutes, $T_{\max }$ (feet) is less than 40 minutes, m.t. (feet) is greater than $34^{\circ} \mathrm{C}$., where each of these values is the mean of the values for the two feet. (It has been found that the behaviour of the feet in this respect is more consistent than that of the hands, and it is the former which is emphasized in the present study. A typical result is shown in Fig. 1.)

The Response in Cretinism: Material and Results

Case 1. A.R., a girl, was aged $4 \frac{1}{2}$ months at the time of the first test.

First child. Born by caesarean section at term. Birth weight $10 \mathrm{lb} .11 \frac{1}{4} \mathrm{oz}$. Had always been difficult to feed and at $4 \frac{1}{2}$ months still took an hour for each feed. A

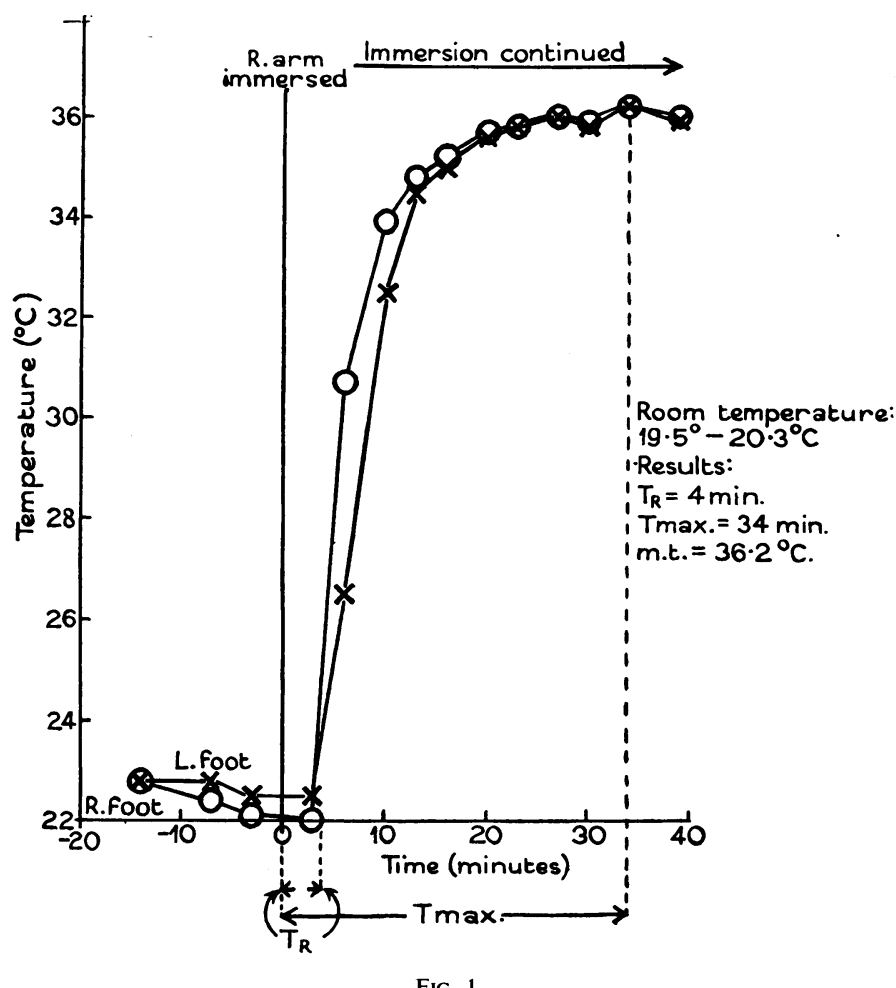

TABLE 1

RESULTS OF REFLEX VASODILATATION TESTS IN THE FEET

\begin{tabular}{|c|c|c|c|c|c|}
\hline \multirow{2}{*}{\multicolumn{2}{|c|}{ Case }} & \multirow{2}{*}{$\begin{array}{l}\text { Weeks after } \\
\text { Start of } \\
\text { Treatment }\end{array}$} & \multicolumn{3}{|c|}{$\begin{array}{l}\text { Response in the Feet } \\
\text { (mean values for the two feet) }\end{array}$} \\
\hline & & & $\underset{\text { (minutes) }}{\mathbf{T}_{\mathbf{R}}}$ & $\underset{\text { (minutes) }}{T_{\max }}$ & $\begin{array}{l}\text { m.t. } \\
\left({ }^{\circ} \mathrm{C} .\right)\end{array}$ \\
\hline A.R. & $\ldots$ & $\begin{array}{r}0 \\
2 \\
3 \\
4 \\
11\end{array}$ & $\begin{array}{l}\text { No rise } \\
34 \\
33 \\
27 \\
2\end{array}$ & $\begin{array}{c}\text { over } 52 \mathrm{mi} \\
56 \\
56+ \\
54+ \\
45\end{array}$ & $\begin{array}{l}29 \cdot 2 \\
22 \cdot 2+ \\
34 \cdot 3+ \\
33 \cdot 4\end{array}$ \\
\hline B.M. & . & $\begin{array}{l}0 \\
3 \\
8\end{array}$ & $\begin{array}{l}\text { No rise } \\
12 \\
<4\end{array}$ & over $\begin{array}{l}55 \mathrm{mi} \\
55+ \\
30\end{array}$ & $\begin{array}{l}33 \cdot 8+ \\
35 \cdot 5\end{array}$ \\
\hline G.E. & $\cdots$ & $\begin{array}{l}\mathbf{0} \\
\mathbf{3}\end{array}$ & $\begin{array}{r}24 \\
6\end{array}$ & $\begin{array}{l}60 \\
33\end{array}$ & $\begin{array}{l}33 \cdot 2 \\
35 \cdot 6\end{array}$ \\
\hline S.G. & .. & $\begin{array}{l}0 \\
4\end{array}$ & $\begin{array}{r}6 \\
<1\end{array}$ & $\begin{array}{l}29 \\
26\end{array}$ & $\begin{array}{l}32 \cdot 9 \\
34 \cdot 2\end{array}$ \\
\hline C.C. & $\cdots$ & $\begin{array}{l}0 \\
3 \frac{1}{2}\end{array}$ & No rise & over $\begin{array}{c}48 \\
22\end{array}$ & $35 \cdot 4$ \\
\hline P.T. & . & 0 & 8 & 28 & $35 \cdot 2$ \\
\hline
\end{tabular}

placid baby. Had been constipated only recently. An umbilical hernia had been present from birth and was increasing in size.

Examination. A typical cretin with a placid expression, coarse features, a dry, yellow, cold skin, protruding tongue, supraclavicular pads of fat, a hoarse monotonous cry, and a very large umbilical hernia. Weight $13 \mathrm{lb} .2 \mathrm{oz}$. Rectal temperature subnormal.

INVESTIGATIONS. Haemoglobin $78 \%$, bone age subnormal, serum cholesterol level $226 \mathrm{mg}$. pér $100 \mathrm{ml}$. and an electrocardiogram showed $T$ waves flat in all leads consistent with mild hypothyroidism.

Progress AND TREaTMENT. Treatment was started on the day of the first test and was continued in the following dosage scheme:

$$
\begin{array}{lll}
\text { 1st to } 10 \text { th day } & \text {. } & \text { grain } \frac{1}{4} \text { daily } \\
\text { 10th to } 16 \text { th day } & \text {.. } & \text { grain } \frac{1}{2} \text { daily } \\
\text { 16th to 23rd day } & \text {. } & \text { grain } \frac{3}{4} \text { daily } \\
\text { 23rd to 36th day } & \text {. } & \text { grain } 1 \text { daily } \\
\text { 36th day onwards } & \text {. } & \text { grain } 1 \frac{1}{2} \text { daily }
\end{array}
$$

Her response was slower than expected and she eventually required more thyroid than does the average cretin at this age.

Reflex Vasodilatation Test (Table 1). Tests were done at intervals after treatment.

First Test. There was no definite evidence of vasodilatation in any limb over 52 minutes (Fig. 2). There were slight temperature rises in the hand and left foot but these indicate an insignificant degree of vasodilatation in this temperature range. The rectal temperature was also recorded, and it is interesting that it rose $0.5^{\circ} \mathrm{C}$. 
during the first 20 minutes. This is evidence of a stimulus which would be quite sufficient to produce a response in the normal.

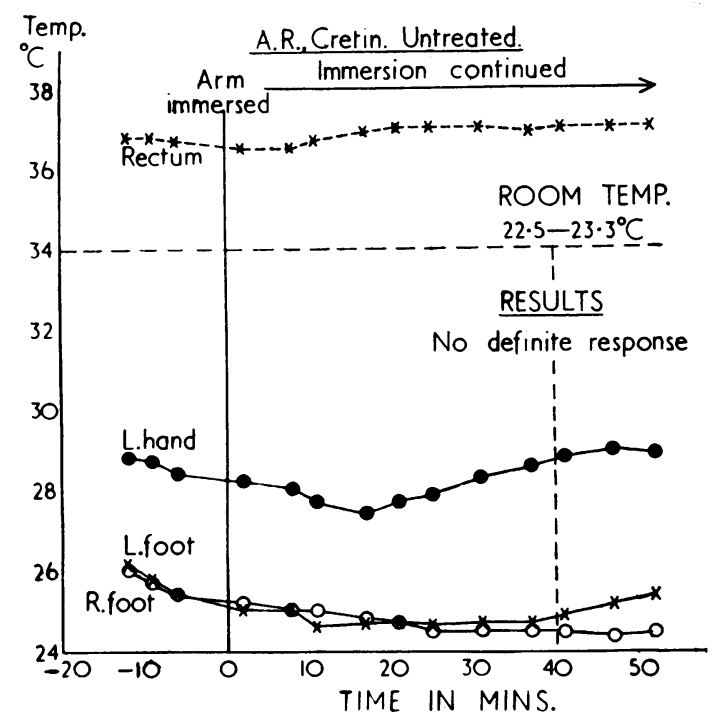

FIG. 2.

Second Test after 14 Days' Treatment. (At this time she had shown a slight but definite response to treatment.) There was a definite but delayed and subnormal response in all three limbs (Fig. 3).

Third and Fourth Tests after 24 and 29 Days' Treatment. The third test gave a response almost identical with that in the second. The fourth test stillshowed delay but the final temperatures were all over $34^{\circ} \mathrm{C}$.

Fifth Test after 11 Weeks' Treatment. (At this time she was normal in appearance and behaviour.) An adult response (Fig. 4) : although $T_{\max }$ and m.t. are slightly outside adult limits this can be accounted for by the fact that she had just come in from the street on a cold day and consequently the initial limb temperatures were unusually low. (The previous tests had been performed as an in-patient.)

Summary. A typical cretin at $4 \frac{1}{2}$ months, her extremities showed no definite response to limb heating over 52 minutes. There was a partial response after two weeks' treatment when she had shown only a slight clinical improvement. There was slight progress towards normality in the limb responses over the next two weeks. After 11 weeks, when she was clinically euthyroid, her temperature curves were of the adult type.

Case 2. B.M., a boy, was aged 6 months at the time of the first test.

First child. Birth weight $9 \frac{1}{4} \mathrm{lb}$. Normal delivery. Had caused no anxiety until he was 4 months old, when his mother realized that he was slow in feeding and was not gaining weight well. Constipated and very lethargic. These symptoms continued until he was brought to hospital at 6 months.

EXAMinATION. A typical cretin with coarse features, dry, yellowish skin, sparse hair, supraclavicular pads of fat, an umbilical hernia, bradycardia, hypothermia and a croaking, monotonous cry. $\mathrm{He}$ had a prolonged reaction time to stimuli. His hands and feet were cold and cyanotic.

INVESTIGATIONS. Haemoglobin $72 \%$.

Progress AND TREATMENT. Thyroid, grain $\frac{1}{8}$ daily, was given orally from the day of the first test. After seven days the dose was increased to grain $\frac{1}{4}$ daily. After three weeks' treatment, at the time of the second test, he had become more lively, was crying more, had lost $1 \mathrm{lb}$. in weight, and his constipation had improved. His appearance was relatively unaltered but his skin was 
loose and hanging in folds. At the time of the third test, after eight weeks' treatment, he was normal in behaviour, active, smiling and chuckling, and almost normal in appearance, the skin texture and colour being much improved and the scalp being covered with new hair.

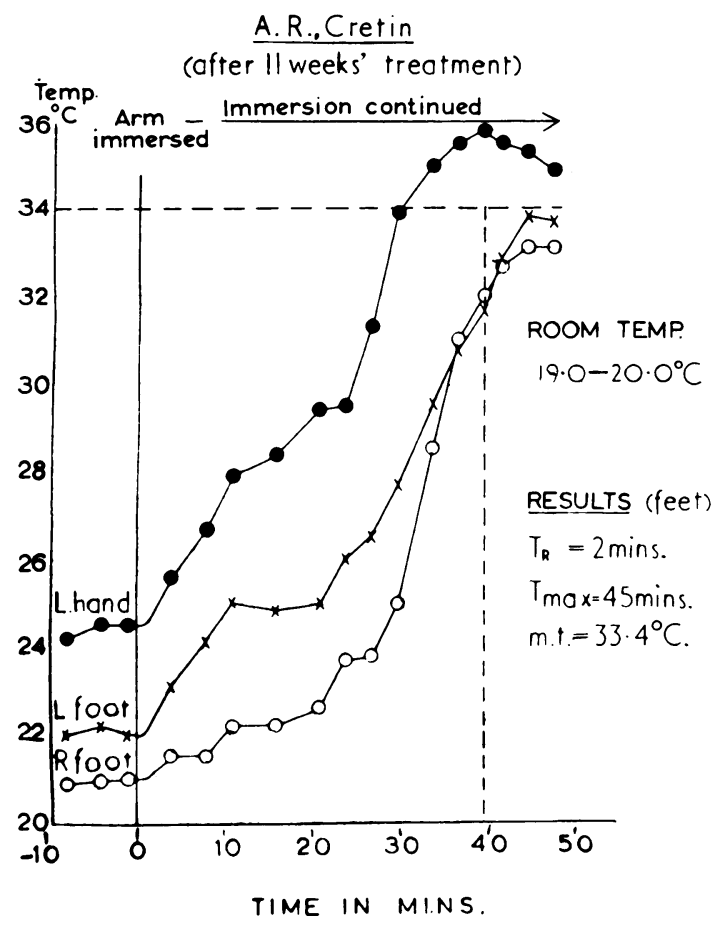

Fig. 4.

Reflex Vasodilatation Tests. The results are shown in Table 1.

First Test. There was no response in any limb over 45 minutes. By the time the test was terminated (55 minutes) the temperature of the hand not immersed had started to rise but there was still no response in the feet.

Second Test after Three Weeks' Treatment. A response in all three limbs but still outside normal limits for the age.

Third Test after Eight Weeks' Treatment. The response was normal in all three limbs.

SUMmary. A typical cretin at 6 months, his extremities showed no response to a heating stimulus over 45 minutes. After three weeks' treatment, when he was just starting to respond clinically, he showed a definite but sluggish response to limb heating. After eight weeks, when he appeared euthyroid, he showed an adult type of response.

Case 3. G.E. was $2 \frac{1}{2}$ years at the time of the first test.

Fifth child. Normal birth and neonatal history. Had always been slow in movements. Retarded motor development (not walking or talking at $2 \frac{1}{2}$ years, and had been standing only for a few months). Skin had always been cold and dry. Always constipated.

EXAMINATION. A typical cretin with coarse features, protruding tongue, pale dry skin, cold and cyanotic extremities, a croaking voice, short neck with supraclavicular pads, and a large abdomen with an umbilical hernia. Under height by $8 \frac{1}{2}$ in. Slightly under weight. Temperature subnormal.

INVESTIGATIONS. Haemoglobin $62 \%$, bone age under 6 months, serum cholesterol level $338 \mathrm{mg}$. per $100 \mathrm{ml}$.

Progress and Treatment. Treatment was started on the day of the first test and was continued on the following dosage scheme:

$$
\begin{array}{lll}
\text { 1st to 10th day } & \ldots & \text { grain } \frac{1}{3} \text { daily } \\
\text { 10th to 22nd day } & \ldots & \text { grain } \frac{1}{2} \text { daily } \\
\text { 22nd day onwards } & \text {. } & \text { grain } \frac{3}{4} \text { daily }
\end{array}
$$

She was more alert and responsive at the time of her second test, after three weeks' treatment. Her skin was warmer and more normal in appearance, and she had lost $1 \mathrm{lb}$. in weight.

Reflex Vasodilatation Tests. The results are shown in Table 1 .

First Test. There was a delayed response in all limbs with low maxima.

Second Test after Three Weeks' Treatment. There was a brisk response with higher maxima-an adult type of response.

Summary. A typical cretin at $2 \frac{1}{2}$ years, she showed a delayed response in all limbs and reached subnormal maxima. After three weeks' treatment the response was normal.

Case 4. S.G., a girl, was aged 2 years 11 months at the time of the first test.

Full term. Normal delivery. Birth weight $8 \mathrm{lb}$. Neonatal period normal. From the age of 3 months feeding had been difficult and during the second year her appetite was extremely poor. Sat up at 12 months, walked at 2 years. First spoke words at 2 years. Teeth first appeared at 10 months. Often was cold to the touch. A fairly active child. Bowel action every other day.

EXAMINATION. An irritable, active child. Under height $(6 \mathrm{in}$.$) . Under weight (6 \mathrm{lb}$.). Appearance not obviously cretinous. Features moderately coarse. Open fontanelle. Fine hair. Waddling gait. Skin dry but not cold, with a yellowish tinge. Temperature subnormal. Some thyroid tissue probably present.

INVESTIGATIONS. Haemoglobin $81 \%$, bone age below 3 months, serum cholesterol level $320 \mathrm{mg}$. per $100 \mathrm{ml}$.

Progress AND TREATMENT. Treatment was started on the day of the first test and was continued on the following dosage scheme:

$\begin{array}{llll}\text { 1st to } 7 \text { th day } & \ldots & \text { grain } \frac{1}{8} \text { daily } \\ \text { 7th to } 14 \text { th day } & \text {. } & \text { grain } \frac{1}{4} \text { daily } \\ \text { 14th day onwards } & \text {. } & \text { grain } \frac{1}{2} \text { daily }\end{array}$

She made slight but definite progress on treatment and at the time of the second test, after four weeks' treatment, she was livelier, looked more normal, and had shed some hair.

Reflex Vasodilatation Tests. The results are shown in Table 1.

First Test. An adult response as regards timing but maximum temperatures slightly subnormal.

Second Test after Four Weeks' Treatment. An adult response. The initial temperatures were higher than on 
the previous occasion (room temperatures on the two occasions only differing by $1 \cdot 0-1 \cdot 5^{\circ} \mathrm{C}$.) and the maximum temperatures were above $34^{\circ} \mathrm{C}$.

Summary. A mild but definite cretin, she responded normally as regards timing but did not attain the usual adult maxima in the feet. After treatment the extremities were much warmer before arm immersion at a comparable room temperature, and she attained normal adult maxima.

Case 5. C.C., a girl, was aged $3 \frac{1}{2}$ years at the time of the first test.

First child. Full term. Forceps delivery. Birth weight $6 \mathrm{lb} .11 \mathrm{oz}$. Had always been a good, quiet child. Late in acquisition of motor facilities (sat up at 12 months, walked at $2 \frac{1}{2}$ years, first spoke at 12 months but had added only a few words to her vocabulary since then). Slow and unsteady on her feet. Hands and feet blue and cold. Always constipated. Only possessed two teeth at 2 years.

Had been treated with thyroid six months before but only for one month.

ExAmination. A moderately severe cretin, although the diagnosis was not immediately obvious. Under height ( $5 \frac{1}{2}$ in.). Under weight (4 lb.). Skin dry and cool. Complexion pale ('strawberries and cream'). Hair sparse. Fontanelle open. Slow in all her movements. Temperature subnormal.

INVESTIGATIONS. Haemoglobin $74 \%$, bone age, marked immaturity, serum cholesterol level $610 \mathrm{mg}$. per $100 \mathrm{ml}$.

Progress AND Treatment. Treatment was started on the day of the first test and was continued on the following dosage scheme:

1st to 12 th day $\quad$. grain $\frac{1}{4}$ daily

12th day onwards $\quad \ldots$ grain $\frac{3}{8}$ daily

She made a definite response to treatment and after three and a half weeks, at the time of the second test, was more lively and less constipated.

RefleX Vasodilatation Tests. The results are set out in Table 1.

First Test. There was no response in the feet over 48 minutes but there was a slow temperature rise in the hand to a maximum below the adult normal.

Second Test after Three and a Half Weeks. An adult response in all three limbs.

SUMmary. A moderately severe cretin who gave no response in the feet and a subnormal response in the hand but after three and a half weeks of treatment showed normal responses in all three limbs.

Case 6. P.T. was aged 7 years at the time of the test. Third child. Full-term. Normal delivery. Birth weight $7 \mathrm{lb} .8 \mathrm{oz}$. In the first year of life had been slow in feeding but a 'model baby' otherwise, not crying. Since then had been slow in acquiring motor facilities and in movement, had been constipated, and no teeth had erupted until the age of 3 years. She was given thyroid intermittently from the age of 6 months to 1 year and continuously since then in a dose of grain $\frac{1}{8-1}+\frac{1}{4}$ daily. She had received none for one month before examination and testing.
Examination. A small, pale, girl with mild but definitely cretinous features. Skin dry and coarse. Neck short. Abdomen protuberant with a small umbilical hernia. Slow in movement and cerebration. Under height (8 in.). Subnormal temperature. Hypotensive $(75 / 55 \mathrm{~mm}$. $\mathrm{Hg})$.

INVESTIGATIONS. Haemoglobin $89 \%$, bone age 'on the low side of normal', serum cholesterol level $332 \mathrm{mg}$. per $100 \mathrm{ml}$., E.C.G. normal, I.Q. $78 \%$.

Progress AND Treatment. Thyroid was given at first in a dose of grain $\frac{3}{4}$ daily and this was gradually increased over the next month to grains 2 daily. On the latter dose she was more alert, her movements were quicker and her constipation had disappeared.

REFLEX VASODILATATION TESTS. The results are shown in Table 1.

First and Second Tests before the Start of Treatment. An adult type of response in all limbs.

Summary. A cretin who had been treated with an inadequate dose of thyroid from the age of 6 months, she showed some but not all of the features of hypothyroidism. Her vasodilatation response was normal even after four weeks without thyroid treatment.

\section{Discussion}

The results in this small series seem quite definite (Table 2). None of the responses were normal for

TABLE 2

SUMMARY OF RESULTS

\begin{tabular}{|c|c|c|c|c|c|c|c|}
\hline \multirow[b]{2}{*}{ Case } & \multirow{2}{*}{$\begin{array}{c}\text { Initial } \\
\text { Test }\end{array}$} & \multicolumn{6}{|c|}{$\begin{array}{l}\text { Subsequent Tests } \\
\text { (Weeks after Start of Treatment) }\end{array}$} \\
\hline & & 1 & 2 & 3 & 4 & 8 & 11 \\
\hline $\begin{array}{l}\text { A.R. } \\
\text { B.M. } \\
\text { G.E. } \\
\text { S.G. } \\
\text { C.C. } \\
\text { P.T. }\end{array}$ & $\begin{array}{l}\mathbf{A} \\
\mathbf{A} \\
\mathbf{P} \\
\mathbf{P} \\
\mathbf{A} \\
\mathbf{N}\end{array}$ & & $\mathbf{P}$ & $\begin{array}{l}\mathbf{P} \\
\mathbf{P} \\
\mathbf{N} \\
\mathbf{N}\end{array}$ & $\begin{array}{l}\mathbf{P} \\
\mathbf{N}\end{array}$ & $\mathbf{N}$ & $\mathbf{N}$ \\
\hline
\end{tabular}

$\mathbf{A}=$ absent response

$\mathbf{P}=$ partial response

the age in the five untreated cases. Two of the three severe cases showed no response at all, and the third showed a slow and inadequate one. The moderately severe case showed no response in the feet and a subnormal one in the hand. The mild case gave a result nearest to the normal, although it cannot be regarded as normal since the response improved on treatment. Only the child who had been treated for most of her life with thyroid produced normal responses.

In all cases the response became normal during replacement therapy.

Before concluding that in cretinism the vasodilatation reflex is in abeyance, however, two other possibilities must be considered:

(1) The inadequate temperature responses are due 
to the thick skin and subcutaneous tissues of the cretin. This explanation might well be true in Case S.G., where there was no delay but the maximum temperature was lower before treatment than afterwards. However, it could not explain the complete failure of the temperature to rise in the three cases A.R., B.M. and C.C. In addition, the fact that in Case S.G. the timing of the response was approximately the same before and after treatment suggests that the insulating effect of myxoedematous tissue is slight.

(2) The peripheral vascular tree is inadequately developed, so that a normal reflex is unable to evoke a normal temperature response because the arterioles or arteriolovenous anastomoses are few or absent. In the myxoedematous adult the skin capillaries have been shown to be few, narrow, and straighter than normal (Zondek, Michael and Kaatz, 1941), and it is likely that this applies to the hypothyroid child also. Information about the state of the arterioles or arteriolovenous anastomoses has not been found, but it is quite likely that they also are reduced in number. This explanation would account for the small difference in the response before and after treatment in Case S.G. but, again, it would not account for the total lack of response in the three patients mentioned. It also seems unlikely that such a complete development of the peripheral vascular tree as would be required to explain the facts could occur in such a short time as three and a half weeks (Case C.C.).

Assuming, then, that the results indicate a failure of the reflex, there are several hypotheses which require consideration. The first is that the response is inhibited by sympathetic overaction. In a disease where all functions are apparently depressed it would be strange if there were any function which was overactive, and this explanation therefore seems unlikely on theoretical grounds. Moreover, it has been shown both in animals and man that sympatheticomimetic effects are enhanced in hyperthyroidism and depressed in hypothyroidism (McCarrison, 1917 ; Lyon, 1923 ; Blau and McNamara, 1930). Finally, there are none of the signs of generalized sympatheticotonia in the cretin such as are found in pink disease where this explanation is likely (Vulliamy, 1952; Bower, 1954). The response to ganglion-blocking agents would have proved or disproved this point. If one of these drugs, administered at the same time as the arm was first immersed in warm water, had had no effect, excessive vasoconstrictor tone would have been disproved. However, it was not considered justifiable to perform this experiment, since the drugs could have had no possible therapeutic value.
Interruption of the reflex pathway at any point would explain the results and it is therefore necessary to consider the anatomy of the reflex pathway, which is nowadays clearly delineated There are two afferent routes from the heated limb. The more important and certainly more easily demonstrated pathway is the venous one (Pickering, 1932; Fatherree and Allen, 1938; Richards, 1946; Snell, 1954). Warmed venous blood travels centripetally and acts upon a thermosensitive centre in the hypothalamus, which is the central relay station of the reflex (Duthie and Mackay, 1940; Fulton, 1943). There has been much less agreement about the existence of an afferent nervous pathway, but recently its existence seems to have been demonstrated conclusively (Kerslake and Cooper, 1950); it is probably situated in the sympathetic system (Cooper and Kerslake, 1953). The efferent pathway is the sympathetic nervous system (Lewis and Pickering, 1931; Freeman, 1935; Fatherree and Allen, 1938; Richards, 1946) and recently it has been shown that the efferent 'stimulus' is entirely inhibitory, i.e., a cessation of the vasoconstrictor impulses normally passing down the sympathetic nerves (Arnott and Macfie, 1948; Gaskell, 1954). The effector organs themselves are the 'strong arterioles' of Lewis and probably the arteriolovenous anastomoses (Grant and Bland, 1931; Barcroft, 1956).

Considering each of these sites in turn as a possible cause of the absence of response, both afferent and efferent sides of the arc can be easily eliminated. There is no reason to think that warmed blood does not travel to the hypothalamus as in the normal. Indeed, the rapid rise of rectal temperature by $0.5^{\circ}$ C. in Case A.R. (Fig. 2) is evidence that it does so. It is most unlikely that the fault lies in a functionless afferent nervous pathway, for this is generally considered to be much less important than the venous pathway. Indeed, for many years its existence was denied. Disturbance of the efferent neurones might seem more likely on first consideration, for a reduction in the excitability of peripheral nerves in hypothyroidism has been demonstrated (Horsten and Boeles, 1949). However, since it is now known that the efferent 'stimulus' is entirely inhibitory, no hypothesis involving neuronal depression at this site can stand.

Depression of hypothalamic function is an attractive possibility, for we know that there is a depression of cerebral function in the cretin, and in animal experiments this has been correlated with immaturity of the sensorimotor cortex in relation to the development of both nerve cells (Eayrs and Taylor, 1951) 
and blood vessels (Eayrs, 1953). And a reduction in blood flow and oxygen uptake in the brains of cretins has been demonstrated (Himwich, Daly, Fazekas and Herrlich, 1942).

Finally, the peripheral vessels themselves may be unable to dilate, although the 'stimulus', the cessation of vasoconstrictor impulses, reaches them. Possibly the walls of the arterioles and/or arteriolovenous anastomoses are the seat of myxoedematous change so that dilatation is physically impossible or possibly local thyroid hormone is necessary for the response to occur.

Whatever the exact mechanism, it is justifiable to conclude from the results that reflex vasodilatation is depressed or absent in cretinism. Although the acral coldness and cyanosis may in part be due to diminished cardiac output, low tissue metabolism and possibly a reduction in the number of peripheral vessels, it is probably the failure of the peripheral vessels to respond reflexly to warming elsewhere which is chiefly responsible.

\section{Summary}

The well-known feature of cretinism, poor peripheral circulation, is considered in the light of possible immaturity of the vasodilatation reflex. Five cases of untreated cretinism are described, together with their incomplete or absent reflex response to warming of one limb; the appearance of a normal response during thyroid medication is demonstrated in all. A sixth case which had been treated with thyroid for long periods gave a normal response. The possible sites of disturbance of the reflex arc are considered, and reasons are given for postulating that either the hypothalamus or the peripheral vessels themselves are at fault. Whatever the precise anatomical site, the poor peripheral circulation in cretinism is probably, in part at least, due to a failure of skin vessels to dilate in response to warming elsewhere.

I wish to thank Professor J. M. Smellie, Dr. Victoria Smallpeice, Dr. H. L. Ellis and Dr. W. H. P. Cant for the opportunity to investigate patients under their care. Fig. 1 is reproduced by permission of the editors of The Quarterly Journal of Medicine.

\section{REFERENCES}

Arnott, W. M. and Macfie, J. M. (1948). J. Physiol. (Lond.), 107, 233. Barcroft, H. (1956). In Peripheral Vascular Disorders, p. 144. Ed. Martin, P., Lynn, B. B., Dible, J. H. and Aird, I. Edinburgh Blau, N. F. and McNamara, H. (1930). Proc. Soc. exp. Biol. (N.Y.), 27, 997.

Bower, B. D. (1954). Quart. J. Med., 23, 215.

(1956). M.D. Thesis, University of Birmingham

Cooper, K. E. and Kerslake. D. McK. (1953). J. Physiol. (Lond.), 119, 18.

Duthie, J. J. R. and Mackay, R. M. I. (1940). Brain, 63, 295.

Eayrs, J. T. (1953). Nature (Lond.), 172, 403.

Fatherree, T. J. and Allen, E. V. (1938). Arch. intern. Med., 62, 1015. Freeman, N. E. (1935). Amer. J. Physiol., 113, 384.

Fulton, J. F. (1943). Physiology of the Nervous System, 2nd ed. pp. 235-6, 251. New York.

Gaskell, P. (1954). Quoted by Barcroft, H. in Peripheral Vascular Disorders, p. 137. Ed. Martin, P., Lynn, R. B., Dible, H. J. and Aird, I. Edinburgh.

Gibbon, J. H. and Landis, E. M. (1932). J. clin. Invest., 11, 1019.

Grant, R. T. and Bland, E. F. (1931). Heart, 15, 385.

Himwich, H. E., Daly, C., Fazekas, J. F. and Herrlich, H. C. (1942), Amer. J. Psychiat., 98, 489.

Horsten, G. P. M. and Boeles, J. T. F. (1949). Arch. int. Pharmacodyn., 78,93

Kerslake, D. McK. and Cooper, K. E. (1950). Clin. Sci., 9, 31

Lewis, T. and Pickering, G. W. (1931). Heart, 16, 33.

Lyon, D. M. (1923). Brit. med. J., 1, 966.

McCarrison, R. (1917). The Thyroid Gland in Health and Disease, p. 177. London.

Pickering, G. W. (1932). Heart, 16, 115.

Richards, R. L. (1946). The Peripheral Circulation in Health and Disease. Edinburgh.

Snell, E. S. (1954). J. Physiol. (Lond.), 125, 361.

Talbot, F. B. (1931). Amer. J. Dis. Child., 42, 965.

Talbot, F. B. (1931). Amer. J. Dis. Child.

Vulliamy, D. G. (1952), Lancet, 2, 1248 . The Diagnosis and Treatment of Endocrine Disorders in Childhood and Adolescence, 1st ed., p. 70. Springfield, Ill.

Zondek, H., Michael, M. and Kaatz, A. (1941). Amer. J. med. Sci., 202, 435 . 